\title{
The relationship of apolipoprotein $B$ and very low density lipoprotein triglyceride with hyperuricemia and gout
}

\author{
Humaira Rasheed ${ }^{1,2}$, Angela Hsu', Nicola Dalbeth³ ${ }^{3}$ Lisa K Stamp ${ }^{4}$, Sally McCormick ${ }^{1}$ and Tony R Merriman ${ }^{\text {* }}$
}

\begin{abstract}
Introduction: Gout results from an innate immune response to monosodium urate (MSU) crystals deposited in joints. Increased very low-density lipoprotein (VLDL) has been associated with gout. The apolipoprotein B (apo B), which is present on VLDL, regulates neutrophil response to MSU crystals and has been positively associated with gout. Furthermore, the gene (A1CF) encoding the complementation factor for the $A P O B$ mRNA-editing enzyme is associated with urate levels. However, the relationship of apo B and VLDL with gout and hyperuricaemia $(H U)$ is still unclear. Therefore, we tested the association of VLDL and apo B with HU and with gout compared to HU.

Methods: New Zealand European ( $n=90)$ and Māori and Pacific Island (Polynesian) $(n=90)$ male gout case and control sample sets were divided into normouricaemia (NU), asymptomatic HU and gout groups. Size exclusion chromatography and enzyme-linked immunosorbant assay was used to measure VLDL and apo B. Multivariate logistic regression was used to assess the risk of gout and HU per unit change in VLDL and apo B.
\end{abstract}

Results: Increased levels of VLDL triglycerides (Tg) were observed in the gout sample set compared to NU and HU in Europeans $\left(P=1.8 \times 10^{-6}\right.$ and $1 \times 10^{-3}$, respectively), but only compared to NU in Polynesians $(P=0.023)$. This increase was driven by increased number of VLDL particles in the European participants and by the Tg-enrichment of existing VLDL particles in the Polynesian participants. Each mmol/L increase in VLDL Tg was significantly associated with gout in the presence of $\mathrm{HU}$ in Europeans, with a similar trend in Polynesians ( $\mathrm{OR}=7.61, P=0.011$ and 2.84, $P=0.069$, respectively). Each $\mu \mathrm{mol} / \mathrm{L}$ increase in total apo $B$ trended towards decreased risk of $H U(O R=0.47 ; P=0.062)$ and, conversely, with increased risk of gout compared to $H U(O R=5.60 ; P=0.004)$.

Conclusions: Increased VLDL Tg is associated with the risk of gout compared to HU. A genetic approach should be taken to investigate the possibility for causality of VLDL in gout. Apolipoprotein B may have pleiotropic effects in determining $\mathrm{HU}$ and gout.

\section{Introduction}

Gout is caused by activation of the innate immune system in response to monosodium urate (MSU) crystals that are deposited in joints when serum urate levels are elevated. The genetic and environmental causal factors in determining hyperuricaemia (HU) are becoming better understood $[1,2]$. However, causal mechanisms in determining gout in the presence of $\mathrm{HU}$ are poorly understood. Along with chylomicrons, very low-density lipoproteins (VLDL) are the lipoproteins that primarily transport triglycerides $(\mathrm{Tg})$

\footnotetext{
* Correspondence: tony.merriman@otago.ac.nz

${ }^{1}$ Department of Biochemistry, University of Otago, 710 Cumberland Street, Dunedin 9052, New Zealand

Full list of author information is available at the end of the article
}

with $86 \%$ and $55 \%$ of their core lipids constituting $\mathrm{Tg}$, respectively. Gout has been associated with increased levels of VLDL Tg in a non-obese and non-drinking male Japanese sample set [3] and type IV hyperlipoproteinaemia (characterized by increased VLDL-Tg) is prevalent in Japanese male gout patients (39\%) [3]. The increased VLDL Tg levels in gout could be caused, at least in part, by reduced lipoprotein lipase activity [4]. Apolipoprotein B (apo B), amongst other lipoproteins, coats MSU crystals exposed to plasma and, when attached to MSU crystals as part of an entire lipoprotein particle, can suppress the stimulation of neutrophils [5]. Based on their previous observation of elevated VLDL components and increased ratio of apolipoprotein CIII (involved in VLDL clearance) 
to CII in hyperuricaemic-hypertriglyceridaemic patients, Cardona et al. [6] demonstrated association of genetic variants at the APOCIII locus with gout. Also, increased VLDL Tg is associated with reduced urinary uric acid excretion [3,7]. Elevated serum apo B levels have also been associated with primary gout [8]. Interestingly, there is association between urate levels and risk of gout of the gene $(A 1 C F)$, which encodes the complementation factor for the APOBEC enzyme that edits apo B mRNA $[9,10]$.

Collectively the observations outlined above implicate VLDL Tg and/or apo B in gout. However, the relationship between VLDL-Tg, apo B and HU and gout is unclear. We hypothesized that if increased VLDL Tg plays a role in regulation of the innate immune response to MSU crystals in gout then this would be consistent with association of VLDL Tg with gout compared to HU. We also tested for association of circulating levels of apo B with $\mathrm{HU}$ and gout compared to HU.

\section{Methods}

\section{Participants}

The 180 New Zealand (NZ) male participants consisted of gout cases, defined by the American Rheumatology Association preliminary classification criteria [11], and controls, who self-reported their lack of gouty arthritis and were at least 17 years of age. Gout cases were recruited from the Auckland and Canterbury regions of NZ. Participants without gout self-reported no diagnosis of gout, and were convenience sampled from the Auckland and Otago regions of NZ. Control participants were stratified into a normouricaemia (NU) group with serum urate level of $<0.41 \mathrm{mmol} / \mathrm{L}$ and a HU group with serum urate level $\geq 0.41 \mathrm{mmol} / \mathrm{L}$. All variables except for biochemical measurements, body mass index (BMI) and medications (obtained from medical records) were selfreported. Ancestry was self-reported and participants were divided into NZ Europeans and NZ Polynesians (Māori and Pacific Island). Demographic, anthropomorphic and clinical data are reported in Table 1. The New Zealand Multi-region Ethics Committee (MEC/ $105 / 10 / 130)$ approved the study and all participants gave written informed consent.

\section{Biochemical measurements}

Fast protein liquid chromatography (FPLC) was used to fractionate lipoproteins from frozen non-fasting serum samples. Tg and cholesterol assays were done on the FPLC fractions to identify lipoprotein-containing fractions. Dilutions of Precipath L (Roche, Mannheim, Germany) were used to make a standard curve and all samples were tested in triplicate. A total of $100 \mu \mathrm{L}$ of each fraction was incubated with $100 \mu \mathrm{L}$ of Tg glycerol-3-phosphate oxidasephenol and aminophenazone (GPO-PAP) reagent (Roche/ Hitachi) or cholesterol oxidase (CHOD)-PAP reagent
(Roche) for 15 to 20 minutes at $37^{\circ} \mathrm{C}$ in a 96-well plate (Nunc $^{\text {тs }}$, Thermo Fisher Scientific, Waltham, MA, USA). Non-fasting serum samples were studied because participants were convenience sampled from health care and community settings.

An enzyme-linked immunosorbant assay (ELISA) was used to measure apo B in serum and FPLC fractions as previously described [12]. Cfas Lipid (Roche) with a known apo B concentration of 2,185 nmol/L was used as an internal control. The primary antibody used for apo B measurement was a polyclonal antibody (Roche) and the secondary antibody was an anti-sheep immunoglobulin G (IgG) conjugated to horseradish peroxidase. Total apo B values obtained from ELISA were adjusted for the percentage lipid recovery from the FPLC. This was done for each individual sample by multiplying the total apo B value by the percentage recovery of plasma lipids from the FPLC. Serum urate was measured by the uricase oxidation method [13] and serum creatinine was measured using the creatinine Jaffé compensated method [14], the end point determined by a Roche Cobas ${ }^{\mathrm{TM}} 8000$ analyser. The estimated glomerular filtration rate (eGFR) was calculated using the Modification of Diet in Renal Disease formula: eGFR $\left(\mathrm{mL} / \mathrm{min} / 1.73 \mathrm{~m}^{2}\right)=175 \times((\mathrm{SCr} \times$ $0.0113)^{-1.154} \times\left(\operatorname{Age}^{-0.203}\right)$.

\section{Statistical analyses}

Due to the skewed distribution of lipid-related phenotypes, all lipid, lipoprotein and apolipoprotein values were expressed as median and interquartile range (25th to 75 th percentile) and pairwise comparisons were done using the Wilcoxon-Mann-Whitney test or Student $t$ test or chi-square test via the Intercooled STATA ${ }^{\mathrm{rm}}$ software version 8.0 (StataCorp, College Station, TX, USA). Multivariate-adjusted linear and logistic regression analyses were used to assess the association of VLDL and other lipid variables with phenotype. A threshold of $P$ $<0.05$ was used to indicate statistical significance.

\section{Results}

Traces of $\mathrm{Tg}$ concentrations in FPLC fractionated lipoproteins (Figure 1) indicate differences in $\mathrm{Tg}$ content in VLDL fractions between the gout and non-gout groups in both Europeans and Polynesians. An increasing trend in serum, total FPLC Tg and VLDL Tg from NU to HU to gout was observed in both Europeans and Polynesians (Table 2). VLDL Tg was significantly higher in gout than $\mathrm{NU}$ and $\mathrm{HU}$ in Europeans (Table 2; $P=1.84 \times 10^{-6}$ and 0.001 , respectively) whereas the difference was significant between NU and gout in Polynesians (Table 2; $P=0.023)$. FPLC is a standard methodology used to separate lipoproteins by size [15]. The area under the curve of the resulting lipoprotein peaks as identified by cholesterol or triglyceride assay can be utilised to establish 
Table 1 Characteristics of the sample sets

\begin{tabular}{|c|c|c|c|c|c|c|}
\hline & \multicolumn{3}{|c|}{ Polynesians } & \multicolumn{3}{|c|}{$P$ values } \\
\hline & NU & HU & Gout & NU vs. HU & NU vs. Gout & HU vs. Gout \\
\hline Number & 30 & 30 & 30 & 30 & 30 & 30 \\
\hline Age (year) & $46.07 \pm 12.18$ & $45.83 \pm 12.32$ & $42.43 \pm 9.95$ & 0.94 & 0.21 & 0.24 \\
\hline Waist circumference $(\mathrm{cm})$ & $105.72 \pm 11.03$ & $111.31 \pm 15.32$ & $110.00 \pm 11.20$ & 0.12 & 0.15 & 0.71 \\
\hline BMI (kg/cm2) & $32.97 \pm 5.60$ & $34.68 \pm 6.06$ & $34.52 \pm 5.31$ & 0.27 & 0.28 & 0.92 \\
\hline $\mathrm{eGFR}\left(\mathrm{mL} / \mathrm{min} / 1.73 \mathrm{~m}^{2}\right)$ & $83.03 \pm 16.14$ & $72.30 \pm 12.35$ & $74.77 \pm 15.36$ & 0.0054 & 0.047 & 0.50 \\
\hline Hypertension (\%) & 17.24 & 16.67 & 26.67 & 0.95 & 0.38 & 0.35 \\
\hline Type 2 diabetes (\%) & 13.33 & 6.67 & 6.9 & 0.39 & 0.41 & 0.97 \\
\hline Statin use (\%) & 13.33 & 13.33 & 30.00 & 0.96 & 0.20 & 0.22 \\
\hline Fibrate use (\%) & - & - & 3.33 & - & - & - \\
\hline Tophi (\%) & - & - & 53.33 & - & - & - \\
\hline Allopurinol use (\%) & - & - & 68.97 & - & - & - \\
\hline Probenecid usage (\%) & - & - & 7.41 & - & - & - \\
\hline Fruit consumption (pieces per day) & $2.62 \pm 1.37$ & $1.88 \pm 1.46$ & $1.23 \pm 0.96$ & 0.051 & $<0.00001$ & 0.049 \\
\hline Sugary drink consumption (drinks per day) & $2.41 \pm 2.40$ & $2.06 \pm 1.91$ & $2.78 \pm 2.07$ & 0.54 & 0.53 & 0.17 \\
\hline Alcohol consumption (drinks/week) & $2.40 \pm 6.02$ & $4.23 \pm 7.95$ & $8.87 \pm 13.53$ & 0.32 & 0.020 & 0.11 \\
\hline \multirow[t]{3}{*}{$\underline{\text { Serum urate }(\mathrm{mmol} / \mathrm{L})^{1}}$} & $0.346 \pm 0.040$ & $0.474 \pm 0.063$ & $0.469 \pm 0.107$ & $<0.00001$ & $<0.00001$ & 0.84 \\
\hline & \multicolumn{3}{|c|}{ Europeans } & \multicolumn{3}{|c|}{$P$ values } \\
\hline & NU & $\mathrm{HU}$ & Gout & NU vs. HU & NU vs. Gout & HU vs. Gout \\
\hline Number & 30 & 30 & 30 & & & \\
\hline Age (year) & $57.67 \pm 12.01$ & $63.17 \pm 13.61$ & $53.60 \pm 9.11$ & 0.10 & 0.14 & 0.0022 \\
\hline Waist circumference $(\mathrm{cm})$ & $92.25 \pm 15.08$ & $99.38 \pm 13.53$ & $107.79 \pm 9.92$ & 0.090 & $<0.00001$ & 0.0096 \\
\hline $\mathrm{BMI}(\mathrm{kg} / \mathrm{cm} 2)$ & $25.73 \pm 6.53$ & $28.85 \pm 6.88$ & $31.27 \pm 4.18$ & 0.12 & 0.0001 & 0.11 \\
\hline eGFR (mL/min/1.73 m²) & $80.18 \pm 12.49$ & $65.91 \pm 16.25$ & $68.86 \pm 17.47$ & 0.0004 & 0.0059 & 0.50 \\
\hline Hypertension (\%) & 23.33 & 36.67 & 46.67 & 0.26 & 0.058 & 0.43 \\
\hline Type 2 diabetes (\%) & 3.45 & 6.9 & 3.33 & 0.55 & 0.98 & 0.53 \\
\hline Statin use (\%) & 20.00 & 23.33 & 16.67 & 0.75 & 0.74 & 0.52 \\
\hline Fibrate use (\%) & - & - & 3.33 & - & - & - \\
\hline Tophi (\%) & - & - & 13.79 & - & - & - \\
\hline Allopurinol use (\%) & - & - & 75.86 & - & - & - \\
\hline Probenecid usage (\%) & - & - & 3.7 & - & - & - \\
\hline Fruit consumption (pieces per day) & $1.68 \pm 1.09$ & $2.27 \pm 1.62$ & $2.00 \pm 1.39$ & 0.11 & 0.33 & 0.50 \\
\hline Sugary drink consumption (drinks per day) & $0.77 \pm 1.27$ & $1.42 \pm 1.77$ & $0.69 \pm 1.04$ & 0.11 & 0.79 & 0.060 \\
\hline Alcohol consumption (drinks/week) & $5.40 \pm 6.13$ & $8.68 \pm 14.72$ & $6.53 \pm 6.06$ & 0.26 & 0.47 & 0.46 \\
\hline Serum urate $(\mathrm{mmol} / \mathrm{L})$ & $0.321 \pm 0.046$ & $0.459 \pm 0.041$ & $0.403 \pm 0.094$ & $<0.00001$ & 0.0001 & 0.0042 \\
\hline
\end{tabular}

${ }^{1}$ In the European gout cases, 17 were $\mathrm{HU}$ and $13 \mathrm{NU}$ at the time of recruitment. In the Polynesian cases, the corresponding numbers were 22 and 8 , respectively. NU: normouricaemia; HU: hyperuricaemia; BMI: body mass index; eGRF: estimated glomerular filtration rate.

ratios of the three major lipoprotein fractions that is VLDL, low-density lipoprotein (LDL) and high-density lipoprotein (HDL). Therefore lipid ratios rather than absolute lipid values were used for further analyses. Significant differences were found in the VLDL Tg to total $\mathrm{Tg}$ ratio between European gout cases and $\mathrm{HU}$ and NU in the three pairwise comparisons (Table 2; $P=0.0041$ to $1.23 \times 10^{-06}$ ), with the ratio increasing from $\mathrm{NU}$ to $\mathrm{HU}$ to gout. However, in the Polynesian groups, this ratio was not significantly different between NU and HU controls $(P=0.44)$ but was significantly increased in gout compared to NU and $\mathrm{HU}(P=0.0071$ and 0.0011 respectively).

The VLDL apo B concentration was significantly higher in $\mathrm{HU}$ and gout cases in Europeans compared to $\mathrm{NU}$ 

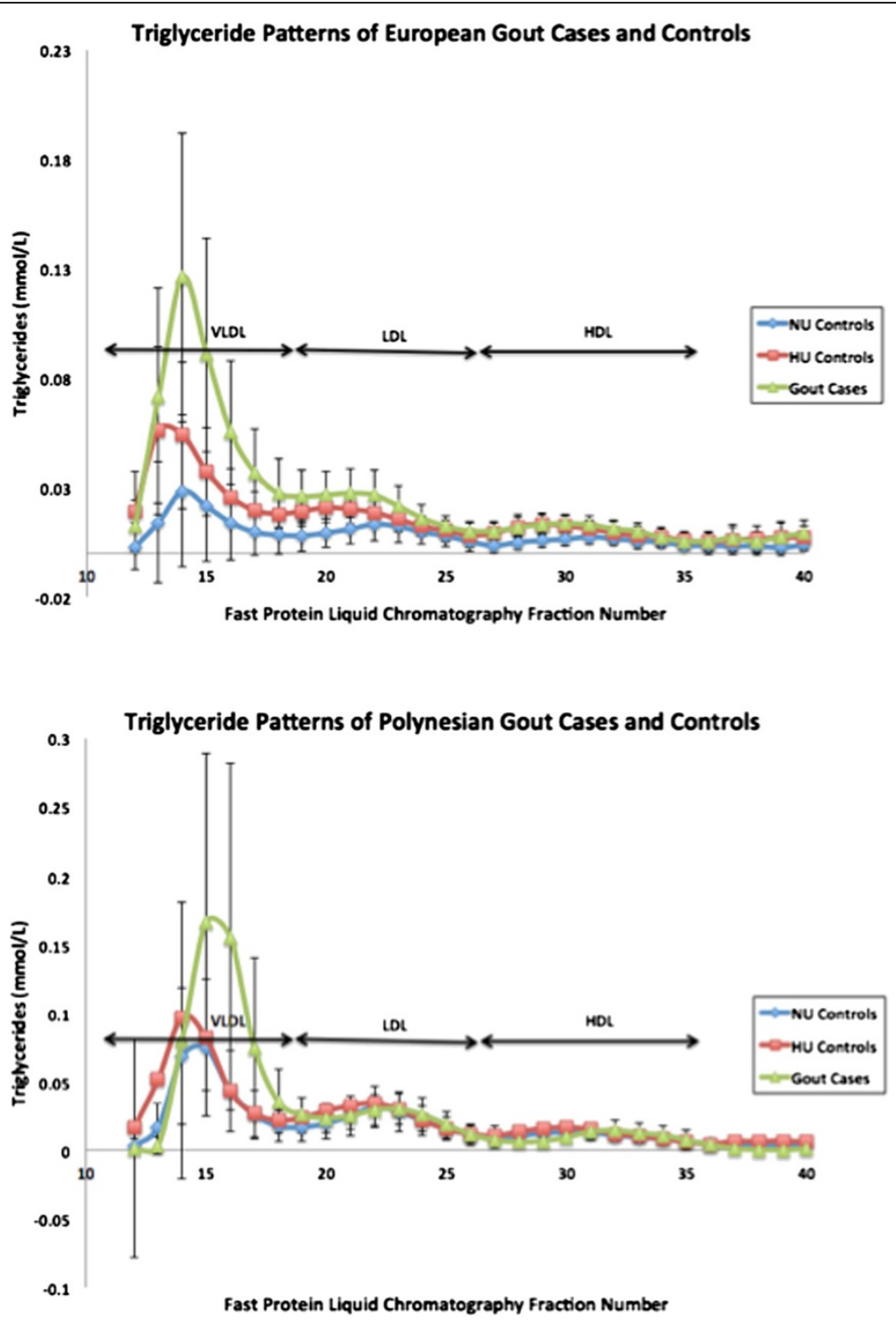

Figure 1 Average triglyceride lipoprotein traces of gout cases and controls. Lipoproteins in plasma samples were separated by fast protein liquid chromatography and each fraction was assayed for triglyceride concentration.

(Table 2; $P=0.018$ and $4.5 \times 10^{-5}$, respectively) and in gout compared to HU $(P=0.041)$. In the Polynesian group the corresponding value for VLDL apo B concentration was not significantly different between gout and the other subgroups, although it was higher in gout. There was a significant increase in the VLDL apo B to total apo B ratio in $\mathrm{HU}$ and gout compared to NU in Europeans and between NU and HU in Polynesians (Table 2). There was no significant difference in the VLDL Tg to VLDL apo B ratio between European subgroups; conversely, in Polynesians, this ratio was higher in gout compared to $\mathrm{HU}$ and $\mathrm{NU}$ (Table 2; $P=0.0011$ and 0.042 , respectively). Collectively these results suggested an increased number of VLDL particles in HU particularly in Europeans, with an increase in
Tg loading of these particles evidenced in gout in Polynesian participants.

We tested the risk of gout compared to NU and $\mathrm{HU}$ for three Tg phenotypes (Table 3; total serum Tg; total FPLC $\mathrm{Tg}, \mathrm{VLDL} \mathrm{Tg}$ ). In the presence of $\mathrm{HU}$ each $\mathrm{mmol} / \mathrm{L}$ increase in VLDL Tg associated with a 7.61-fold increase in risk in Europeans $(P=0.011)$ and a trend towards increased risk in Polynesians (odds ratio $(\mathrm{OR})=2.84$; $P=0.069$ ), with significantly increased risk in the combined ancestral groups $(\mathrm{OR}=3.56 ; P=0.002)$. These results were robust to exclusion of gout cases taking fenofibrates or statins (Table 4). A significant effect was seen for total FPLC Tg in Europeans comparing gout to $\mathrm{HU}(\mathrm{OR}=5.19$ per unit $\mathrm{mmol} / \mathrm{L}$ increase, $P=0.014)$ but 
Table 2 Fast protein liquid chromatography lipid measurements

\begin{tabular}{|c|c|c|c|c|c|c|}
\hline & \multicolumn{6}{|c|}{ Polynesians } \\
\hline & $\begin{array}{l}\text { NU median } \\
\text { [25th-75th percentile] }\end{array}$ & $\begin{array}{l}\text { HU median } \\
\text { [25th-75th percentile] }\end{array}$ & $\begin{array}{l}\text { Gout median } \\
\text { [25th-75th percentile] }\end{array}$ & $P$ NU vs. HU & P NU vs. Gout & $P$ HU vs. Gout \\
\hline Number & 30 & 30 & 30 & & & \\
\hline Total serum cholesterol & $5.71[4.33-6.47]$ & $5.73[5.03-6.54]$ & $5.99[5.25-6.41]$ & 0.48 & 0.47 & 0.86 \\
\hline Total FPLC cholesterol & $4.75[3.52-5.47]$ & $4.16[3.72-4.81]$ & $4.00[3.18-4.43]$ & 0.25 & 0.074 & 0.41 \\
\hline LDL cholesterol & $2.83[2.20-3.22]$ & $2.45[2.14-3.09]$ & $2.45[1.99-2.97]$ & 0.42 & 0.11 & 0.40 \\
\hline HDL cholesterol & $1.13[0.84-1.35]$ & $0.96[0.79-1.00]$ & $0.77[0.70-1.06]$ & 0.030 & 0.0052 & 0.17 \\
\hline Total serum $\mathrm{Tg}$ & $1.87[1.15-3.04]$ & $2.32[1.83-3.29]$ & $2.49[1.46-4.36]$ & 0.058 & 0.060 & 0.93 \\
\hline Total FPLC Tg & $1.41[0.97-2.16]$ & $1.55[1.23-1.80]$ & $1.71[1.09-2.85]$ & 0.34 & 0.17 & 0.46 \\
\hline VLDL Tg & $0.57[0.37-1.18]$ & $0.80[0.61-1.06]$ & $1.01[0.60-2.11]$ & 0.24 & 0.023 & 0.10 \\
\hline VLDL Tg:Total Tg & $0.45[0.32-0.61]$ & $0.51[0.43-0.60]$ & $0.65[0.53-0.75]$ & 0.44 & 0.0071 & 0.0011 \\
\hline Total apo B ( $\mu \mathrm{mol} / \mathrm{L})$ & 1.09 [0.93-1.85] & 0.94 [0.79-1.13] & $1.10[0.92-1.26]$ & 0.026 & 0.59 & 0.020 \\
\hline VLDL apo B $(\mu \mathrm{mol} / \mathrm{L})$ & $0.044[0.028-0.079]$ & $0.072[0.045-0.101]$ & $0.061[0.028-0.132]$ & 0.048 & 0.32 & 0.92 \\
\hline VLDL apo B:Total apo B & $0.040[0.025-0.077]$ & $0.072[0.050-0.11]$ & $0.051[0.022-0.121]$ & 0.001 & 0.19 & 0.40 \\
\hline \multirow[t]{2}{*}{ VLDL Tg:VLDL apo B } & $12.49[7.95-20.14]$ & $11.74[8.23-15.26]$ & 19.44 [13.61-25.83] & 0.74 & 0.042 & 0.0011 \\
\hline & & & Europeans & & & \\
\hline Number & 30 & 30 & 30 & & & \\
\hline Total serum cholesterol & $5.56[4.75-6.09]$ & $5.60[4.93-6.39]$ & $5.11[4.27-6.59]$ & 0.77 & 0.37 & 0.36 \\
\hline Total FPLC cholesterol & $4.18[3.73-4.86]$ & $4.01[3.19-4.70]$ & $4.19[3.28-5.10]$ & 0.21 & 0.70 & 0.50 \\
\hline LDL cholesterol & $2.51[2.06-2.97]$ & $2.45[1.86-2.83]$ & $2.37[1.83-3.59$ & 0.46 & 0.68 & 0.75 \\
\hline HDL cholesterol & $1.27[1.21-1.57]$ & $1.01[0.79-1.21]$ & $1.00[0.89-1.10]$ & $2.14 \mathrm{E}-05$ & 0.0001 & 0.79 \\
\hline Total serum $\mathrm{Tg}$ & $1.58[1.05-2.00]$ & $1.92[1.50-2.80]$ & $2.45[1.70-2.90]$ & 0.019 & 0.0008 & 0.21 \\
\hline Total FPLC Tg & $1.11[0.64-1.35]$ & $1.15[0.90-1.41]$ & $1.57[1.23-2.25]$ & 0.17 & 0.0001 & 0.0021 \\
\hline VLDL Tg & $0.36[0.16-0.47]$ & $0.47[0.35-0.65]$ & $0.84[0.59-1.30]$ & 0.008 & $1.84 \mathrm{E}-06$ & 0.0010 \\
\hline VLDL Tg:Total Tg & $0.32[0.24-0.41]$ & $0.43[0.35-0.50]$ & $0.68[0.49-0.60]$ & 0.0041 & $1.23 \mathrm{E}-06$ & 0.0004 \\
\hline Total apo B ( $\mu \mathrm{mol} / \mathrm{L})$ & 1.31 [1.09-1.65] & $1.06[0.72-1.42]$ & $1.36[1.03-1.76]$ & 0.036 & 0.88 & 0.053 \\
\hline VLDL apo B ( $\mu \mathrm{mol} / \mathrm{L})$ & $0.038[0.021-0.072]$ & $0.064[0.035-0.103]$ & $0.090[0.062-0.125]$ & 0.018 & 4.53E-05 & 0.041 \\
\hline VLDL apo B:Total apo B & $0.032[0.019-0.054]$ & $0.063[0.043-0.090]$ & $0.069[0.051-0.092]$ & 0.0001 & 8.59E-06 & 0.37 \\
\hline VLDL Tg:VLDL apo B & $8.33[4.76-13.61]$ & $8.62[5.74-12.56]$ & $10.45[7.41-13.72]$ & 0.92 & 0.16 & 0.16 \\
\hline
\end{tabular}

All $P$ values are calculated using the Wilcoxon-Mann-Whitney test. NU: normouricaemia; HU: hyperuricaemia; FPLC: fast protein liquid chromatography; LDL: low-density lipoprotein; HDL: high-density lipoprotein; Tg: triglyceride; VLDL: very low-density lipoprotein; apo B: apolipoprotein B.

not Polynesians $(\mathrm{OR}=1.52, P=0.31)$. There was no significant risk in gout associated with total serum $\mathrm{Tg}$.

We next investigated apo B. It was notable that total apo B was significantly lower in HU than in NU in both ancestral groups $\left(P_{\text {European }}=0.036, \quad P_{\text {Polynesian }}=0.026\right)$ (Table 2). Given also the association in Europeans with serum urate of the $A 1 C F$ gene [9], which encodes a complementation factor for the apolipoprotein B mRNAediting enzyme catalytic polypeptide 1 [16], we tested the hypothesis that apo B is associated with $\mathrm{HU}$ by comparing total serum apo B levels between NU and combined HU/gout groups (Table 5). Each unit increase $(\mu \mathrm{mol} / \mathrm{L})$ in total circulating apo B was significantly associated with reduced risk of $\mathrm{HU}$ in Polynesians $(\mathrm{OR}=0.20$ [0.04 to 0.96], $P=0.044)$ but not in Europeans
(OR $=0.46$ [0.15 to 1.46$], P=0.19)$ with trending evidence for a protective role in $\mathrm{HU}$ in the combined sample sets $(\mathrm{OR}=0.47$ [0.21 to 1.04$], P=0.062)$. In contrast, each $100 \mathrm{nmol} / \mathrm{L}$ increase in VLDL apo B was not associated with an increased risk of $\mathrm{HU}$ in Europeans (OR $=4.04$ [0.82 to 19.83], $P=0.086)$ or Polynesians (OR $=1.81$ [0.51 to 6.47], $P=0.36$ ) although there was evidence for increased risk of $\mathrm{HU}$ in the combined sample sets $(\mathrm{OR}=$ 2.50 [1.00 to 6.26], $P=0.050$ ). There was, however, by linear regression analysis no association of apo $\mathrm{B}$ with urate levels in the combined NU and HU groups (Table 5). We also tested for a role of total circulating apo B in gout compared to HU (Table 3), observing positive association with gout $(\mathrm{OR}=5.60$ [1.73 to 18.18 ], $P=0.004 \mathrm{per} \mu \mathrm{mol} / \mathrm{L}$ unit change) although there was no evidence for association 
Table 3 Analysis of association of gout risk with lipid and apo B-associated traits in study sample sets

\begin{tabular}{|c|c|c|c|c|c|c|c|c|}
\hline & NU vs. Gout & & & & HU vs. Gout & & & \\
\hline & $\begin{array}{l}\text { Unadjusted OR } \\
{[95 \% \mathrm{Cl}]}\end{array}$ & $P$ & $\begin{array}{l}\text { Adjusted OR } \\
\text { [95\% Cl] }\end{array}$ & $P$ & $\begin{array}{l}\text { Unadjusted OR } \\
{[95 \% \mathrm{Cl}]}\end{array}$ & $P$ & $\begin{array}{l}\text { Adjusted OR } \\
\text { [95\% Cl] }\end{array}$ & $P$ \\
\hline Total Tg (mr & & & & & & & & \\
\hline Europeans & 2.34 [1.22-4.49] & 0.011 & 1.37 [0.70-2.65] & 0.36 & 1.21 [0.73-1.99] & 0.46 & 1.31 [0.72-2.40] & 0.38 \\
\hline Polynesians & 1.41 [1.00-1.98] & 0.049 & 1.00 [0.51-1.98] & 0.99 & 1.17 [0.85-1.62] & 0.34 & 1.14 [0.75-1.75] & 0.54 \\
\hline Combined & $1.59[1.17-2.17]$ & 0.003 & 1.19 [0.80-1.75] & 0.39 & $1.18[0.90-1.54]$ & 0.24 & 1.20 [0.88-1.65] & 0.25 \\
\hline Total FPLC T & & & & & & & & \\
\hline Europeans & 4.17 [1.51-11.51] & 0.006 & $1.97[0.75-5.15]$ & 0.17 & 4.37 [1.49-12.81] & 0.007 & 5.19 [1.39-19.33] & 0.014 \\
\hline Polynesians & $1.29[0.80-2.10]$ & 0.30 & $0.65[0.28-1.50]$ & 0.31 & 1.51 [0.82-2.78] & 0.19 & $1.52[0.68-3.41]$ & 0.31 \\
\hline Combined & $1.74[1.14-2.64]$ & 0.01 & 1.17 [0.69-1.96] & 0.56 & $2.05[1.23-3.42]$ & 0.006 & 2.14 [1.17-3.90] & 0.014 \\
\hline VLDL Tg (m & & & & & & & & \\
\hline Europeans & 11.29 [2.40-53.00] & 0.002 & 3.24 [0.87-12.07] & 0.080 & 6.52 [1.70-24.99] & 0.006 & 7.61 [1.60-36.26] & 0.011 \\
\hline Polynesians & $1.92[1.01-3.67]$ & 0.048 & $0.98[0.34-2.81]$ & 0.97 & $2.46[1.11-5.44]$ & 0.026 & $2.84[0.92-8.76]$ & 0.069 \\
\hline Combined & 2.78 [1.55-4.99] & 0.001 & $1.81[0.87-3.75]$ & 0.11 & 3.19 [1.62-6.24] & 0.001 & 3.56 [1.60-7.92] & 0.002 \\
\hline Total apoB ( & & & & & & & & \\
\hline Europeans & $0.97[0.36-2.63]$ & 0.95 & $0.83[0.18-3.76]$ & 0.81 & $2.71[0.94-7.76]$ & 0.064 & $3.32[0.87-12.61]$ & 0.078 \\
\hline Polynesians & 0.47 [0.18-1.23] & 0.12 & $0.27[0.04-1.73]$ & 0.17 & $13.38[1.48-120.76]$ & 0.021 & 33.55 [1.16-972.93] & 0.041 \\
\hline Combined & $0.65[0.34-1.26]$ & 0.20 & 0.78 [0.32-1.93] & 0.59 & 3.60 [1.41-9.17] & 0.007 & $5.60[1.73-18.18]$ & 0.004 \\
\hline VLDL apo B & & & & & & & & \\
\hline Europeans & $17.80[2.99-106.02]$ & 0.002 & $10.05[1.16-87.35]$ & 0.036 & $1.69[0.74-3.86]$ & 0.21 & $1.67[0.62-4.51]$ & 0.31 \\
\hline Polynesians & $2.24[0.89-5.60]$ & 0.086 & $1.97[0.48-8.12]$ & 0.35 & $1.51[0.61-3.73]$ & 0.38 & $2.42[0.70-8.36]$ & 0.16 \\
\hline Combined & 4.23 [1.87-9.59] & 0.001 & 2.68 [1.03-6.95] & 0.043 & 1.60 [0.87-2.93] & 0.13 & 1.57 [0.80-3.09] & 0.19 \\
\hline VLDL Tg:VLL & & & & & & & & \\
\hline Europeans & $1.06[0.97-1.16]$ & 0.20 & 1.02 [0.90-1.16] & 0.78 & $1.06[0.97-1.17]$ & 0.20 & $1.02[0.91-1.15]$ & 0.68 \\
\hline Polynesians & 1.05 [0.99-1.10] & 0.086 & 1.03 [0.99-1.07] & 0.19 & 1.08 [1.01-1.15] & 0.024 & 1.08 [0.99-1.18] & 0.061 \\
\hline Combined & 1.04 [1.00-1.09] & 0.051 & $1.03[0.99-1.06]$ & 0.15 & $1.06[1.01-1.12]$ & 0.016 & $1.06[1.00-1.12]$ & 0.045 \\
\hline
\end{tabular}

Adjusted for age, BMI, type 2 diabetes, SSB intake (drinks/day), alcohol intake (drinks/week), eGFR, hypertension and prescription of lipid-lowering medication. The Polynesian data are also adjusted by number of self-reported Polynesian grandparents. The combined analysis was additionally adjusted by ancestral group. NU: normouricaemia; HU: hyperuricaemia; OR: odds ratio; Cl: confidence interval; Tg: triglyceride; FPLC: fast protein liquid chromatography; VLDL: very low-density lipoprotein; apo B: apolipoprotein B; BMI, body mass index; SSB: sugar-sweetened beverage; eGRF: estimated glomerular filtration rate.

of VLDL apo $\mathrm{B}(\mathrm{OR}=1.57$ [0.80 to 3.09$], P=0.19$ per $100 \mathrm{nmol} / \mathrm{L}$ unit change). Thus apo B negatively correlated with $\mathrm{HU}$, but positively correlated with gout in the presence of $\mathrm{HU}$.

Given the organised chronic inflammatory nature of the tophus, with inflammatory factors that may promote resolution of gout attacks [17] and thus create a different inflammatory situation in acute tophaceous gout, we repeated the Table 3 analysis, but with tophaceous cases excluded (Table 4). Despite the exclusion of $53 \%$ of the Polynesian and $14 \%$ of the European cases, the significance of the total apo B and VLDL Tg: VLDL Apo B ratio analyses in the previous HU compared to gout analysis (Table 3$)$ were strengthened $(\mathrm{OR}=11.58, P=0.001 \mathrm{com}$ pared with $\mathrm{OR}=5.60, P=0.004$ and $\mathrm{OR}=1.07, P=0.029$ compared to $\mathrm{OR}=1.06, P=0.005$ respectively).

\section{Discussion}

We observed increased levels of VLDL Tg in gout compared to asymptomatic HU. This increase was suspected to be driven by overproduction of VLDL particles in HU particularly in Europeans (as evidenced by a significantly higher VLDL apo B to total apo B ratio in HU and gout; Table 2) and additionally by the Tg-enrichment of existing VLDL particles (a significantly higher VLDL Tg to VLDL apo B ratio in gout; Table 2) in the Polynesian participants only. The association of each $\mathrm{mmol} / \mathrm{L}$ increase in VLDL Tg with risk of gout in the presence of $\mathrm{HU}$ was restricted to Europeans $(\mathrm{OR}=7.61, P=0.011)$, although there was a trend towards increased risk in Polynesian participants $(\mathrm{OR}=2.84, P=0.069)$. We also associated reduced total apo B with $\mathrm{HU}$ and increased total apo B with gout compared to HU. Given this is a 
Table 4 Analysis for association of gout risk with lipid and apo B-associated traits in non-tophaceous gout (left) and gout excluding participants taking fenofibrate and statins (right)

\begin{tabular}{|c|c|c|c|c|}
\hline & \multicolumn{2}{|c|}{ HU vs non-tophaceous gout } & \multicolumn{2}{|c|}{ HU vs lipid-lowering excluded gout } \\
\hline & Adjusted OR [95\% Cl] & $P$ & Adjusted OR [95\% Cl] & $P$ \\
\hline \multicolumn{5}{|c|}{ Total Tg (mmol/L) } \\
\hline Europeans & $1.11[0.55-2.26]$ & 0.77 & $1.30[0.367-2.51]$ & 0.44 \\
\hline Polynesians & $0.95[0.50-1.80]$ & 0.88 & $1.16[0.68-1.96]$ & 0.59 \\
\hline Combined & $1.04[0.72-1.50]$ & 0.82 & $1.24[0.86-1.78]$ & 0.25 \\
\hline \multicolumn{5}{|c|}{ Total FPLC Tg (mmol/L) } \\
\hline Europeans & $3.64[0.96-13.82]$ & 0.068 & $7.41[1.42-38.56]$ & 0.017 \\
\hline Polynesians & $1.05[0.29-3.77]$ & 0.94 & $1.58[0.62-4.05]$ & 0.34 \\
\hline Combined & $1.78[0.91-3.48]$ & 0.091 & $2.37[1.17-4.83]$ & 0.017 \\
\hline \multicolumn{5}{|c|}{ VLDL Tg (mmol/L) } \\
\hline Europeans & $5.10[0.97-26.81]$ & 0.054 & $26.15[2.48-276.04]$ & 0.007 \\
\hline Polynesians & $1.72[0.37-7.96]$ & 0.49 & $3.18[0.84-12.05]$ & 0.089 \\
\hline Combined & $2.78[1.13-6.79]$ & 0.025 & $4.77[1.76-12.96]$ & 0.002 \\
\hline \multicolumn{5}{|c|}{ Total apo B ( $\mu \mathrm{mol} / \mathrm{L})$} \\
\hline Europeans & $4.32[0.86-21.69]$ & 0.075 & 3.17 [0.71-14.09] & 0.13 \\
\hline Polynesians & 158.22 [1.95-1286.5] & 0.024 & $7.23[0.28-189.08]$ & 0.24 \\
\hline Combined & $11.58[2.62-51.15]$ & 0.001 & 4.32 [1.17-15.93] & 0.028 \\
\hline \multicolumn{5}{|c|}{ VLDL apo B $(0.1 \mu \mathrm{mol} / \mathrm{L})$} \\
\hline Europeans & 1.99 [0.67-5.91] & 0.22 & $1.85[0.52-6.57]$ & 0.34 \\
\hline Polynesians & $0.39[0.04-3.82]$ & 0.42 & $1.80[0.50-6.49]$ & 0.37 \\
\hline Combined & $1.32[0.63-2.77]$ & 0.46 & $1.64[0.74-3.63]$ & 0.23 \\
\hline \multicolumn{5}{|c|}{ VLDL Tg:VLDL apo B } \\
\hline Europeans & $1.06[0.93-1.21]$ & 0.39 & $1.05[0.92-1.20]$ & 0.43 \\
\hline Polynesians & $1.48[1.02-2.15]$ & 0.041 & $1.11[1.00-1.24]$ & 0.060 \\
\hline Combined & $1.07[1.01-1.15]$ & 0.029 & $1.07[1.00-1.14]$ & 0.042 \\
\hline
\end{tabular}

Table 5 Association analysis of apo B with hyperuricaemia (left) and serum urate (right)

\begin{tabular}{|c|c|c|c|c|c|c|c|c|}
\hline & \multicolumn{4}{|c|}{ NU vs. HU and gout } & \multicolumn{4}{|c|}{ Vs. urate in $\mathrm{NU}$ and $\mathrm{HU}$ groups } \\
\hline & $\begin{array}{l}\text { Unadjusted OR } \\
{[95 \% \mathrm{Cl}]}\end{array}$ & $P$ & $\begin{array}{l}\text { Adjusted OR } \\
{[95 \% \mathrm{Cl}]}\end{array}$ & $P$ & $\begin{array}{l}\text { Unadjusted } \beta \\
{[95 \% \mathrm{Cl}]}\end{array}$ & $P$ & $\begin{array}{l}\text { Adjusted } \beta \\
{[95 \% \mathrm{Cl}]}\end{array}$ & $P$ \\
\hline \multicolumn{9}{|c|}{ Total apo B ( $\mu \mathrm{mol} / \mathrm{L})$} \\
\hline Europeans & $0.58[0.24-1.39]$ & 0.22 & $0.46[0.15-1.46]$ & 0.19 & $-0.026[-0.071-0.019]$ & 0.26 & $-0.014[-0.048-0.020]$ & 0.41 \\
\hline Polynesians & $0.27[0.10-0.75]$ & 0.012 & $0.20[0.04-0.96]$ & 0.044 & $-0.038[-0.071-0.004]$ & 0.031 & $-0.017[-0.057-0.023]$ & 0.40 \\
\hline Combined & $0.41[0.22-0.77]$ & 0.005 & $0.47[0.21-1.04]$ & 0.062 & $-0.034[-0.061-0.007]$ & 0.013 & $-0.020[-0.045-0.005]$ & 0.12 \\
\hline \multicolumn{9}{|c|}{ VLDL apo B $(0.1 \mu \mathrm{mol} / \mathrm{L})$} \\
\hline Europeans & $8.13[2.04-32.42]$ & 0.003 & $4.04[0.82-19.83]$ & 0.086 & $0.046[0.011-0.081]$ & 0.011 & $0.001[-0.002-0.004]$ & 0.48 \\
\hline Polynesians & $2.32[0.89-6.05]$ & 0.084 & $1.81[0.51-6.47]$ & 0.36 & $0.045[-0.007-0.098]$ & 0.089 & $-0.002[-0.004-0.0004]$ & 0.099 \\
\hline Combined & $3.80[1.74-8.33]$ & 0.001 & $2.50[1.00-6.26]$ & 0.050 & $0.046[0.017-0.075]$ & 0.002 & $-0.001[-0.003-0.0005]$ & 0.18 \\
\hline
\end{tabular}

Adjusted for age, BMI, type 2 diabetes, SSB intake (drinks/day), alcohol intake (drinks/week), eGFR, hypertension and prescription of lipid-lowering medication. The Polynesian data are also adjusted by number of self-reported Polynesian grandparents. The combined analysis was additionally adjusted by ancestral group. NU: normouricaemia; HU: hyperuricaemia; OR: odds ratio; Cl: confidence interval; apo B: apolipoprotein B; VLDL: very low-density lipoprotein; BMI, body mass index; SSB: sugar-sweetened beverage; eGRF: estimated glomerular filtration rate. 
cross-sectional observational study, these results cannot ascribe causality to VLDL Tg and/or apo B in HU and in gout compared to HU. However the data, when considered with the previous literature, support further investigation of the role of VLDL Tg and/or apo B in HU and gout.

Apo B has been linked with downregulation of the innate immune system and the resolution phase of acute gout. When coating MSU crystals apo B suppresses neutrophil activation [5] (which is needed for endocytosis and lysis of these crystals in gout [18]). This is consistent with the clinical observation that apo B coats MSU crystals only when inflammation subsides in gout [19]. Apo B possesses domains enriched in positively charged amino acids, which have high affinity for binding to polyanionic molecules such as MSU crystals [20]. Our data, however, that associate increased levels of apo B with gout compared to $\mathrm{HU}$ are not necessarily inconsistent with the previous experimental evidence. It is possible that increased circulating apo B correlate with reduced synovial apo B in intercritical gout (all our participants were intercritical), which would reduce the suppression of innate immunity and increase the chance of acute gout. This hypothesis could be tested by measuring apo B and VLDL apo B in synovial fluid in NU, HU and gout. The maintenance of the association of apo B with gout compared to $\mathrm{HU}$ when tophaceous cases were excluded suggests heterogeneity and that future studies investigating a possible role for apo B in gout should stratify into tophaceous vs nontophaceous gout. Recently a male gout patient with mitochondriopathy in Kearns-Sayre syndrome (KSS) was described [21]. This person had large MSU crystals that were less immunogenic and that exhibited little synergy with toll-like receptor 2 agonists, a response that was hypothesised to be due to different crystal conformational or chemicophysical properties. It would be interesting to evaluate the lipoprotein profile of MSU crystals from the KSS patient compared to non-syndromic gout patients.

Reduced total apo B was associated with $\mathrm{HU}$ whereas increased total apo B was associated with gout compared to HU. These observations suggest pleiotropic effects of apo B in gout. Previously, serum urate control in Europeans has been associated with genetic variation in the A1CF gene [9], which encodes a complementation factor for the apo B mRNA-editing enzyme catalytic polypeptide 1 (APOBEC). This enzyme is part of a complex that edits a translational stop codon within the apo B mRNA, causing synthesis of apo B-48 (present on chylomicrons) instead of the full-length apo B-100. In humans, this editing takes place in the intestine whereas apo B-100 (present on VLDL and LDL) is exclusively produced by the liver [22]. While it has not been confirmed if $A 1 C F$ is the causal gene at this locus, the maximally associated genetic variants at this locus all map within $A 1 C F$ [9] suggesting that this gene does control urate levels. The genetic data are consistent with our association of reduced total apo B levels with $\mathrm{HU}$ and lead to the prediction that the urate-increasing $A 1 C F$ allele would functionally associate with reduced apo B. Collectively these data raise the possibility that reduced apo $B$ is a risk factor for HU, yet increased VLDL Tg (with a single apo B molecule per VLDL particle) could be involved in gout in the presence of $\mathrm{HU}$.

The fibric acid derivative fenofibrate is used in hypertriglyceridaemia to reduce VLDL, LDL and total triglycerides. It activates peroxisome proliferator-activated receptor alpha, which in turns activates lipoprotein lipase to reduce circulating Tg-rich particles [23]. In primary hypertriglyceridaemia fenofibrate reduces serum urate by increasing renal uric acid excretion via inhibition of urate transporter $1[24,25]$ and reduces Tg levels without changing serum apo B levels [26]. Interestingly, the established serum urate-increasing response to an acute fructose load (ref [27] and refs therein) is negated by fenofibrate [26], suggesting a link with carbohydrate metabolism. Fenofibrate is not used as a primary management tool in gout, although its use is associated with maintenance of normouricaemia after withdrawal of frontline urate-lowering therapy in gout [28] and small trials show efficacy as an adjunct treatment for gout [29-31]. Our data, demonstrating a possible role for VLDL in gout compared to HU are consistent with previous evidence [26] supporting the use of fenofibrate as an adjunct treatment in gout with hypertriglyceridaemia.

One possible limitation of our study relates to the nonfasting status of the participants. This would have introduced additional variability into the $\mathrm{Tg}$ but not the apo B data - in a study of healthy subjects at four and eight hours postprandially, total apo B did not differ whereas total Tg levels increased when compared to fasting [32]. It is important to point out, however, non-fasting $\mathrm{Tg}$ and other lipids are better predictors of cardiovascular disease [33], supporting the use of non-fasting measures in studying metabolic risk.

Consideration of genetic data does support the hypothesis that aspects of $\mathrm{Tg}$ metabolism play a causal role in gout. For example, there are loci associated with control of serum urate levels that contain genes that are also associated with serum Tg levels (GCKR, MLXIPL, A1CF) [9] and gout [9,10]. A Mendelian randomization study, examining the relationship between the genetically attributable fractions of urate and triglyceride, provides evidence for a causal role of triglycerides in urate control but not the reverse [34]. These genetic data and the observational data presented herein support further testing of the hypothesis that apo B and VLDLTg play a causal role in gout. For example, in large sample sets genetic variants associated with apo B and VLDL Tg could be tested for association with gout compared to HU controls. 


\section{Conclusions}

We report association of reduced total apo B with $\mathrm{HU}$, but increased apo B and VLDL Tg with gout compared to HU. These data support the hypothesis that VLDL metabolism plays a role in gout, with apo B having pleiotropic effects.

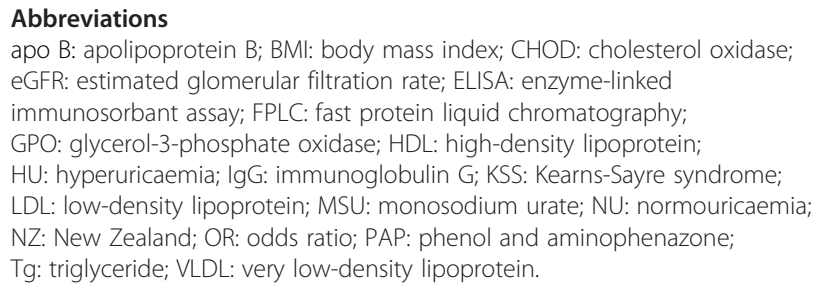

\section{Competing interests}

The authors declare that they have no competing interests.

\section{Authors' contributions}

$H R, A H, S M$ and TRM helped to design the study, oversee its execution, and prepare the manuscript. ND and LKS helped to provide clinical recruitment and prepare the manuscript. All authors read and approved the final manuscript.

\section{Acknowledgements}

This work was supported by the Health Research Council of New Zealand, Arthritis New Zealand, New Zealand Lottery Health and the University of Otago. The authors would like to thank Jill Drake, Meaghan House and Gabrielle Sexton for assistance in recruitment. All participants who gifted samples and information for this study are sincerely thanked.

\section{Author details}

'Department of Biochemistry, University of Otago, 710 Cumberland Street, Dunedin 9052, New Zealand. ${ }^{2}$ Department of Chemistry, University of Engineering and Technology, G.T. Road, Lahore 54890, Pakistan. ${ }^{3}$ Department of Medicine, University of Auckland, Park Road, Auckland 1010, New Zealand. ${ }^{4}$ Department of Medicine, University of Otago, 2 Riccarton Avenue, Christchurch 8140, New Zealand.

Received: 9 July 2014 Accepted: 17 November 2014 Published online: 29 November 2014

\section{References}

1. Merriman TR, Choi HK, Dalbeth N: The genetic basis of gout. Rheum Dis Clin North Am 2014, 40:279-290.

2. Singh JA, Reddy SG, Kundukulam J: Risk factors for gout and prevention: a systematic review of the literature. Curr Opin Rheumatol 2011, 23:192-202.

3. Matsubara K, Matsuzawa Y, Jiao S, Takama T, Kubo M, Tarui S: Relationship between hypertriglyceridemia and uric acid production in primary gout. Metabolism 1989, 38:698-701.

4. Tsutsumi Z, Yamamoto T, Moriwaki Y, Takahashi S, Hada T: Decreased activities of lipoprotein lipase and hepatic triglyceride lipase in patients with gout. Metabolism 2001, 50:952-954.

5. Terkeltaub R, Curtiss LK, Tenner AJ, Ginsberg MH: Lipoproteins containing apoprotein $B$ are a major regulator of neutrophil responses to monosodium urate crystals. J Clin Invest 1984, 73:1719-1730.

6. Cardona F, Tinahones FJ, Collantes E, Escudero A, García-Fuentes E, Soriguer $\mathrm{F}$ : Contribution of polymorphisms in the apolipoprotein Al-CIII-AIV cluster to hyperlipidaemia in patients with gout. Ann Rheum Dis 2005, 64:85-88.

7. Tinahones F, Collantes E, C-Soriguer F, Gonzalez-Ruiz A, Pineda M, Anon J, Guijo PS: Increased VLDL levels and diminished renal excretion of uric acid in hyperuricaemic-hypertriglyceridaemic patients. Rheumatology 1995, 34:920-924.

8. Ulreich A, Kostner G, Pfeiffer K, Sedlmayr P, Rainer F: Serum lipids and lipoproteins in patients with primary gout. Rheumatol Int 1985, 5:73-77.

9. Köttgen A, Albrecht E, Teumer A, Vitart V, Krumsiek J, Hundertmark C, Pistis G, Ruggiero D, O'Seaghdha CM, Haller T, Yang Q, Tanaka T, Johnson AD, Kutalik Z, Smith AV, Shi J, Struchalin M, Middelberg RP, Brown MJ, Gaffo AL,
Pirastu N, Li G, Hayward C, Zemunik T, Huffman J, Yengo L, Zhao JH, Demirkan A, Feitosa MF, Liu X, et al: Genome-wide association analyses identify 18 new loci associated with serum urate concentrations. Nat Genet 2013, 45:145-154.

10. Phipps-Green A, Merriman M, Topless R, Altaf S, Montgomery GW, Franklin C, Jones GT, van Rij AM, White D, Stamp LK, Dalbeth N, Merriman TR: Twenty-eight loci that influence serum urate levels: analysis of association with gout. Ann Rheum Dis 2014. doi: 10.1136/annrheumdis2014-205877. [Epub ahead of print]

11. Wallace SL, Robinson H, Masi AT, Decker JL, McCarty DJ, Yu TF: Preliminary criteria for the classification of the acute arthritis of primary gout. Arthritis Rheum 1977, 20:895-900.

12. Marcovina SM, Albers JJ, Gabel B, Koschinsky M, Gaur V: Effect of the number of apolipoprotein (a) kringle 4 domains on immunochemical measurements of lipoprotein (a). Clin Chem 1995, 41:246-255.

13. Sanders G, Pasman A, Hoek F: Determination of uric acid with uricase and peroxidase. Clin Chim Acta 1980, 101:299-303.

14. Foster-Swanson A, Swartzentruber M, Roberts P, Feld R, Johnson M, Wong S: Reference interval studies of the rate-blanked creatinine/Jaffe method on BM/Hitachi systems in six US laboratories. Clin Chem 1994, 40:1057.

15. Innis-Whitehouse W, Li X, Brown WW, Le N-A: An efficient chromatographic system for lipoprotein fractionation using whole plasma. J Lipid Res 1998, 39:679-690

16. Hu P, Lu L, Hu B, Qin YH: Recapture of hepatic apolipoprotein B mRNA editing may be a promising strategy to relieve nephrotic dyslipidemia. Med Hypotheses 2010, 75:561-563.

17. Dalbeth N, Pool B, Gamble GD, Smith T, Callon KE, McQueen F, Cornish J: Cellular characterization of the gouty tophus: a quantitative analysis. Arthritis Rheum 2010, 62:1549-1556.

18. Dalbeth N, Haskard D: Mechanisms of inflammation in gout. Rheumatology 2005, 44:1090-1096.

19. Ortiz-Bravo E, Sieck MS, Ralph Schumacher H: Changes in the proteins coating monosodium urate crystals during active and subsiding inflammation. Immunogold studies of synovial fluid from patients with gout and of fluid obtained using the rat subcutaneous air pouch model. Arthritis Rheum 1993, 36:1274-1285.

20. Hirose N, Blankenship DT, Jackson RL, Cardin AD: Isolation and characterization of four heparin-binding cyanogen bromide peptides of human plasma apolipoprotein B. Biochemistry 1987, 26:5505-5512.

21. Jansen $T L$, Berendsen $D$, Crisan $T O$, Cleophas MCP, Janssen MCH, Joosten LAB: New gout test: enhanced ex vivo cytokine production from PBMCS in common gout patients and a gout patient with Kearns-Sayre syndrome. Clin Rheumatol 2014, 33:1341-1346.

22. Hirano K, Min J, Funahashi T, Baunoch D, Davidson N: Characterization of the human apobec-1 gene: expression in gastrointestinal tissues determined by alternative splicing with production of a novel truncated peptide. J Lipid Res 1997, 38:847-859.

23. Staels B, Dallongeville J, Auwerx J, Schoonjans K, Leitersdorf E, Fruchart J-C: Mechanism of action of fibrates on lipid and lipoprotein metabolism. Circulation 1998, 98:2088-2093.

24. Uetake D, Ohno I, Ichida K, Yamaguchi Y, Saikawa H, Endou H, Hosoya T: Effect of fenofibrate on uric acid metabolism and urate transporter 1. Internal Med 2010, 49:89-94.

25. Desager JP, Hulhoven R, Harvengt C: Uricosuric effect of fenofibrate in healthy volunteers. J Clin Pharmacol 1980, 20:560-564.

26. Bastow $M$, Durrington $P$, Ishola $M$ : Hypertriglyceridemia and hyperuricemia: effects of two fibric acid derivatives (bezafibrate and fenofibrate) in a double-blind, placebo-controlled trial. Metabolism 1988, 37:217-220.

27. Dalbeth N, House ME, Gamble GD, Horne A, Pool B, Purvis L, Stewart A, Merriman M, Cadzow M, Phipps-Green A, Merriman TR: Population-specific influence of SLC2A9 genotype on the acute hyperuricaemic response to a fructose load. Ann Rheum Dis 2013, 72:1868-1873.

28. Perez-Ruiz F, Herrero-Beites AM, Carmona L: A two-stage approach to the treatment of hyperuricemia in gout: The "dirty dish" hypothesis. Arthritis Rheum 2011, 63:4002-4006.

29. Lee Y-H, Lee C-H, Lee J: Effect of fenofibrate in combination with urate lowering agents in patients with gout. Korean J Internal Med 2006, 21:89-93.

30. Takahashi S, Moriwaki Y, Yamamoto T, Tsutsumi Z, Ka T, Fukuchi M: Effects of combination treatment using anti-hyperuricaemic agents with fenofibrate and/or losartan on uric acid metabolism. Ann Rheum Dis 2003, 62:572-575. 
31. Feher M, Hepburn A, Hogarth M, Ball S, Kaye S: Fenofibrate enhances urate reduction in men treated with allopurinol for hyperuricaemia and gout. Rheumatology 2003, 42:321-325.

32. Otokozawa S, Ai M, Diffenderfer MR, Asztalos BF, Tanaka A, Lamon-Fava S, Schaefer EJ: Fasting and postprandial apolipoprotein B-48 levels in healthy, obese, and hyperlipidemic subjects. Metabolism 2009, 58:1536-1542.

33. Mora S, Rifai N, Buring JE, Ridker PM: Fasting compared with nonfasting lipids and apolipoprotein for predicting incident cardiovascular events. Circulation 2008, 118:993-1001.

34. Rasheed H, Hughes K, Flynn TJ, Merriman TR: Mendelian randomisation provides no evidence for a causal role of serum urate in increasing serum triglyceride levels. Circ Cardiovasc Genet 2014. doi:10.1161/ CIRCGENETICS.114.000556. [Epub ahead of print]

doi:10.1186/s13075-014-0495-z

Cite this article as: Rasheed et al:: The relationship of apolipoprotein B and very low density lipoprotein triglyceride with hyperuricemia and gout. Arthritis Research \& Therapy 2014 16:495.

\section{Submit your next manuscript to BioMed Central and take full advantage of:}

- Convenient online submission

- Thorough peer review

- No space constraints or color figure charges

- Immediate publication on acceptance

- Inclusion in PubMed, CAS, Scopus and Google Scholar

- Research which is freely available for redistribution 